\title{
Cannulation of the Coronary Sinus via the Femoral Vein-A New Technique
}

\author{
Demosttienes Katritsis, M.D., PH.D., FACC, AND Michael M. WebB-PEPLOE, FRCP* \\ Departments of Cardiology, Onassis Cardiac Surgery Center, Athens, Greece, and *St Thomas's Hospital, London, England
}

\section{Summary}

Background: Cannulation of the coronary sinus usually has been accomplished by advancing a catheter through the subclavian or internal jugular veins.

Hypothesis: We have developed a new technique for cannulation of the coronary sinus with a modified 6F Judkins L5 coronary catheter positioned through the femoral vein.

Results: The technique was tried successfully in 20 consecutive patients by the same operator and the average fluoroscopy time for coronary sinus cannulation was $1.6 \pm 1.0 \mathrm{~min}$.

Conclusion: Analysis of the results showed evidence of a learning curve with improvement of time with an increasing number of patients. The method provides a safe and inexpensive solution for catheterization of the coronary sinus, easily accessible to every catheter laboratory.

Key words: coronary sinus

\section{Introduction}

Cannulation of the coronary sinus has usually been accomplished by advancing a catheter through the subclavian internal jugular or brachial vein., 2 These approaches entail the discomfort of an extra puncture for the patient and in certain cases may be particularly cumbersome. Subclavian puncture, in addition, is associated with a certain risk of complications, even when it is aided by ultrasound guidance. ${ }^{3}$ Recently, the development of deflectable catheters for electrophysiology

Address for reprints:

Dr D. Katritis

Onassis Cardiac Surgery Center

356 Sygrou Ave

17674 Athens, Greece

Received: September 25, 1996

Accepted with revision: January 24, 1997 purposes has allowed the cannulation of the coronary sinus through the femoral vein. ${ }^{4}$ We have developed a new technique for the cannulation of the coronary sinus with ordinary, open-lumen catheters positioned through the femoral vein.

\section{Methods}

Following Seldinger puncture of the right femoral vein, a $7 \mathrm{~F}$ sheath is introduced. The distal curved tip of a $6 \mathrm{~F}$ Judkins L5 coronary catheter is carefully removed with a surgical blade (Fig. 1) and care is taken not to leave sharp edges on the new tip. A long $(3 \mathrm{~m})$, straight, 0.032 " wire is then introduced in the catheter. Advancement of the wire up to the end of the catheter results into straightening of its distal part (Fig. 2), while withdrawal of the wire allows the catheter to regain its normal shape (Fig. 3). In this way, a "deflectable" catheter is achieved that is almost similar to the one used by the electrophysiology catheters. The catheter is introduced over the guidewire into the right ventricular apex. The wire is partially withdrawn, allowing the catheter to regain part of its curved shape, and the catheter is then withdrawn toward the septal insertion of the tricuspid valve and simultaneously rotated clockwise until a slight forward movement indicates engagement of the coronary sinus os. Depending upon the anatomy of the area, this engagement requires full or partial withdrawal of the wire. Following engagement of the os, the wire is advanced into the sinus, and by clockwise rotation and gentle forward pushing the catheter is advanced over the wire deeply into the sinus (Fig. 4). Although the 6F catheter provides the necessary flexibility for easy manipulation, it has the disadvantage of a narrow lumen, and blood samples taken through the catheter are often hemolyzed. This problem can be overcome either by the creation of holes into the distal part of the catheter after removal of the tip, or by exchanging the catheter with a 7F A2 multipurpose catheter over the long wire.

\section{Results}

The technique was tried by the same operator in 20 consecutive patients participating in a study requiring coronary sinus blood samples. In the first four cases, opacification of coro- 


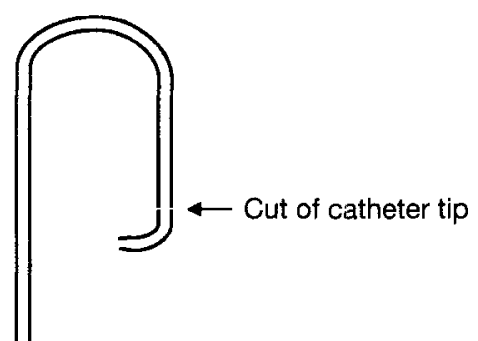

FIG. I The distal curve of the Judkins catheter is removed in a manner that leaves a catheter with a straight distal end.

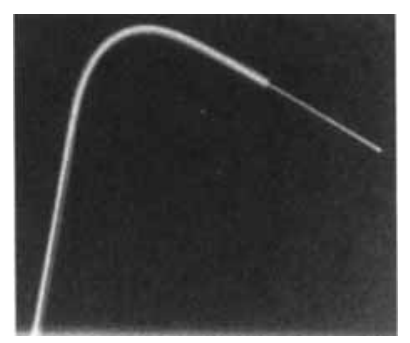

Fig. 2 Advancement of the wire up to the end of the catheter and straightening of its distal part.

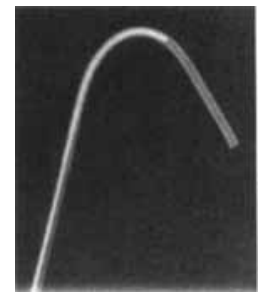

FIG. 3 Withdrawal of the wire allows the catheter to regain its normal shape.

nary sinus following coronary injections was used to identify the exact position of the os; in the remaining patients, cannulation was attempted without previous visualization of the coronary sinus. Once the femoral vein was cannulated with the sheath, the average fluoroscopy time to advance the $6 \mathrm{~F}$ left Judkins to the coronary sinus successfully was $1.6 \pm 1.0 \mathrm{~min}$. Analysis of the results showed evidence of a learning curve with improvement of time with an increasing number of patients (Fig. 5). Apart from occasional atrial ectopic beats, no serious complications were noted.

\section{Discussion}

Apart from clinical electrophysiology and ablation studies, cannulation of the coronary sinus is needed for measurements of certain metabolites during interventions, for coronary sinus

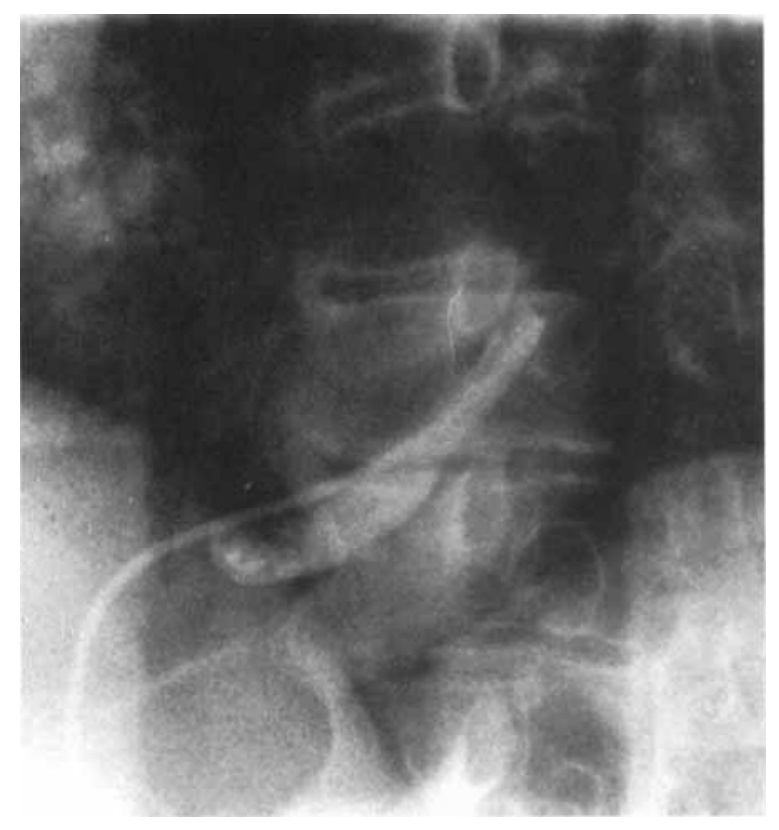

FIG. 4 Placement of the Judkins catheter within the coronary sinus verified by contrast injection.

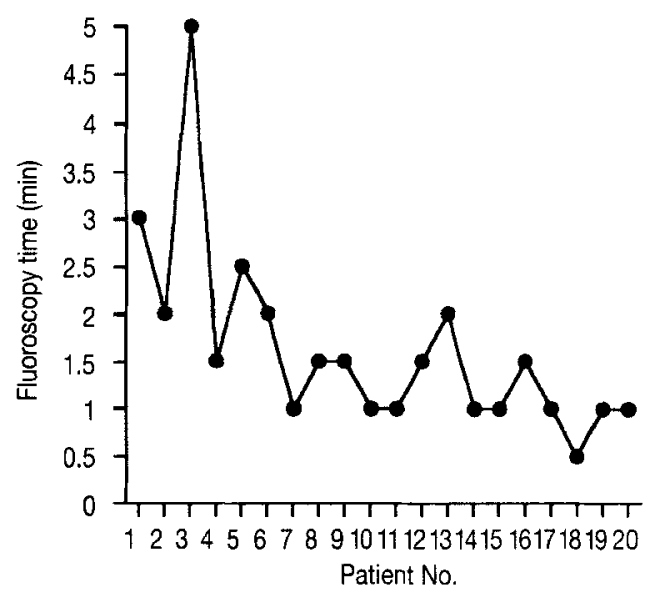

FIG. 5 Learning curve for the technique.

blood flow assessment, and for coronary sinus retroperfusion for myocardial protection during ischemia. ${ }^{1.2}$ The method described allows easy cannulation of the coronary sinus without the need for subclavian or jugular punctures and without the use of special catheters. ${ }^{5}$ The removal of the tip needs to be done carefully to avoid an abrasive new catheter with sharp edges. This was usually achieved with a careful cut and, oceasionally, with additional trimming of the new tip. In any case, manipulation of the catheter is performed most of the time while the soft end of the wire is protruding outside the catheter tip, thus minimizing the possibility of intimal trauma. It should be stated that the operator is an electrophysiologist with considerable experience in coronary sinus cannulation; thus, the 
anticipated times for application of our technique may be more frequent for operators with less exposure to these techniques. Nevertheless, the method provides a safe and inexpensive solution easily accessible to every catheter laboratory.

\section{References}

1. Zalewski A, Goldberg S, Slysh S, Maroko PR: Myocardial protection via coronary sinus interventions: Superior effects of arterialization compared with intermittent occlusion. Circulation 1985;71: $1215-1223$
2. Golino P, Piscione F, Benedict CR, Anderson HV, Cappelli-Gigarzi $\mathrm{M}$, Indolfi C, Condorelli M, Chiariello M, Willerson JT: Local effect of serotonin released during coronary angioplasty. $N$ Engl J Med 1994;330:523-528

3. Mansfield PF, Hohn DC, Fornage BD, Gregurich MA. Ota DM: Complications and failures of subclavian vein catheterization. $N$ Engl J Med 1994;551:1735-1738

4. Katritsis D, Ward DE: Ablation of cardiac arrhythmias. In Heart Disease, 2nd ed. (Eds. Julian DG, Camm AJ, Fox KM. Hall RJC. Poole-Wilson PA), p. 636-647. Philadelphia: W.B. Saunders, 1996

5. Hamaoka K, Itoi T, Nakagawa M, Kamiya Y, Suwada T: Coronary sinus cannulation via the femoral vein. Pediat Cardiol 1989;10: 91-92 